(จ) ICEJP

Instituto Centroamericano de

Estudios Jurídicos y Políticos

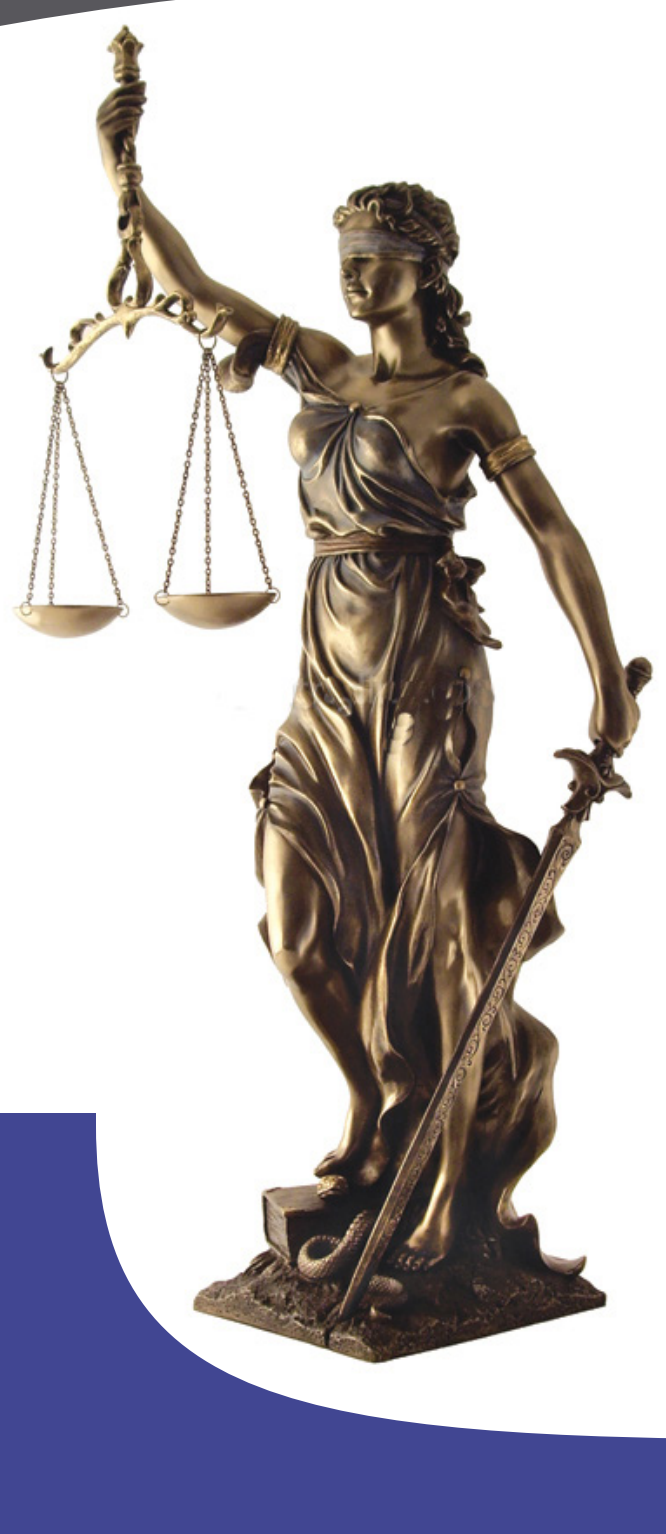

Danny Ramírez Ayérdiz - Caio Varela José Alejandro Castillo - Mario Isaías Tórrez Jerson Cerda Tijerino - Jessye Saavedra Conrado

- Román De Antoni - Waldir Ruiz

ISSN 2413-810X 


\title{
Los derechos humanos como paradigma de la educación en la universidad: Del capital bumano a la emancipación del sujeto $^{12}$
}

\author{
Danny Ramírez Ayérdiz | Caio Varela
}

\section{RESUMEN}

Recibido: 01.06.15/Aceptado: 18.08.15

Con el enflaquecimiento de la vocación de bienestar de los Estados y la proliferación del capitalismo neoliberal, los gobiernos han propiciado, a través de las estructuras de educación, una acelerada transformación de la funcionalidad social de la educación, hacia una funcionalidad de mercado. Boaventura de Sousa adjudica esta nueva funcionalidad de mercado de la universidad "a una crisis institucional", como consecuencia del actuar de las dictaduras latinoamericanas del pasado y el subsecuente neoliberalismo que llegó o continuó con la democracia al "poner la universidad al servicio del proyectos modernizantes autoritarios, abriendo al sector privado la producción del bien público de la universidad y obligando a la universidad pública a competir en condiciones desleales en el emergente mercado de los servicios universitarios".

\section{PALABRAS CLAVE}

Capitalismo, derecho a la educación, derechos humanos, dignidad humana, currículo, capitalismo educativo, educación liberadora.

\begin{abstract}
With the weight of the vocation of welfare States and the proliferation of neoliberal capitalism, Governments have led, through the structures of education, an accelerated transformation of the social functionality of education, towards a market functionality. Boaventura de Sousa awarded this new functionality of the University market "to an institutional crisis", as a result of acting of Latin American dictatorships of the past and the subsequent neo-liberalism that became or continued with democracy to "put the University at the service of modernizing authoritarian project, opening production of the public good of the University to the private sector and forcing the public University to compete on unfair conditions in the emerging market of University services"
\end{abstract}

KEYWORDS

Capitalism, right to education, human rights, human dignity, educational capitalism and liberating education.

\footnotetext{
1 Este ensayo ha sido elaborado como parte de la entrega final para la materia Derechos Económicos, Sociales y Culturales de la Maestría Derechos Humanos y Democratización en América Latina y el Caribe, cohorte 2014-2015, organizada por la Universidad Nacional de San Martín, Argentina. Se agradece las sugerencias de los docentes de esta materia, Julieta Rossi y Diego Morales. Asimismo, agradecemos los comentarios y observaciones de Erika Ledesma.

2 Este trabajo fue presentado en el VI Coloquio Latinoamericano de Educación en Derechos Humanos realizado los días 28, 29 y 30 de septiembre de 2015 en Quilmes, Argentina.
} 


\section{Derecho a la educación y universidad en el actual contexto capitalista}
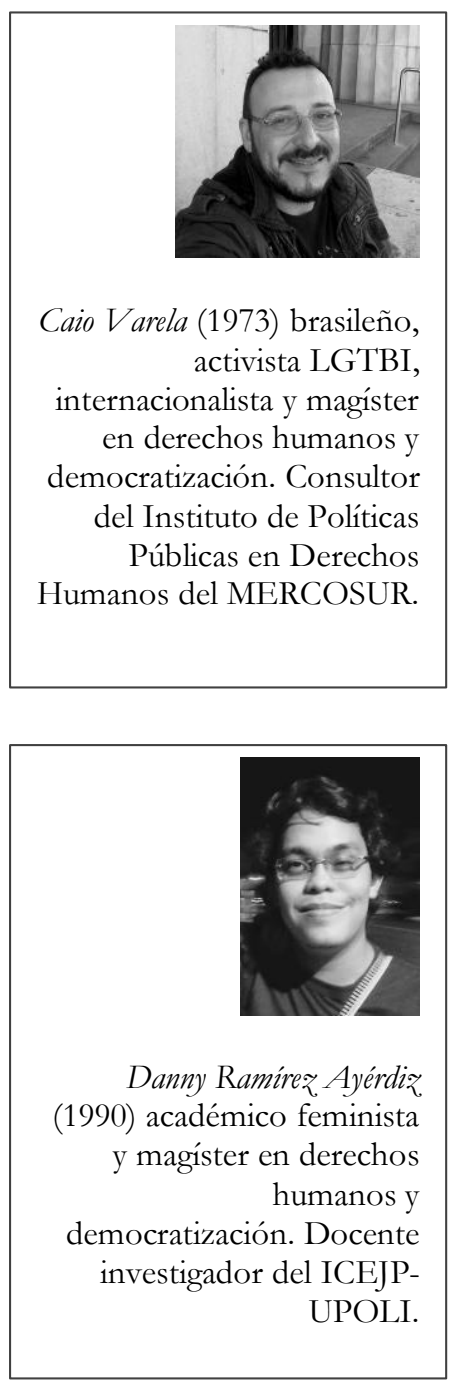

$\mathrm{E}$ 1 derecho a la educación, es una prerrogativa fundamental innegable para el desarrollo de la persona en sociedad. Como instrumento pedagógico formal, permite el avance de la autonomía individual basada en el conocimiento de los progresos de la ciencia y las letras. En su carácter de motor de la autonomía personal, la educación proclama el desarrollo del pensamiento humano como su fin al que sirven el conocimiento y el avance científico.

El carácter de instrumento y a la vez de motor para la autonomía personal que tiene el derecho a la educación, da cuenta de su eje intergeneracional, en cuanto a su ubicación en las clásicas generaciones de derechos humanos. En otras palabras, el derecho a la educación es per se desencadenador y garantía para el disfrute de otros derechos, de ahí su intergeneracionalidad, sostenida por el Comité de Derechos Económicos, Sociales y Culturales (Comité DESC) en su Observación General Número 11,"Planes de acción para la enseñanza primaria (art. 14)":

... [el derecho a la educación $]^{1}[\mathrm{~s}] \mathrm{e}$ ha clasificado de distinta manera como derecho económico, derecho social y derecho cultural. Es, todos esos derechos al mismo tiempo. También, de muchas formas, es un derecho civil y un derecho político, ya que se sitúa en el centro de la realización plena y eficaz de esos derechos. A este respecto, el derecho a la educación es el epítome de la indivisibilidad y la interdependencia de todos los derechos humanos. ${ }^{2}$

\footnotetext{
${ }^{1} \mathrm{El}$ texto inserto entre corchetes es agregado.

${ }^{2}$ Naciones Unidas, "Recopilación de las Observaciones Generales y Recomendaciones Generales adoptadas por órganos creados en virtud de tratados de derechos humanos: Observación General Número 11", Comité DESC, $20^{\circ}$ Período de Sesiones (1999), Párr. 2, Consultada 16 de mayo de http://www.servindi.org/pdf/ObservacionesyRecomendacionesGenerales.pdf
} 


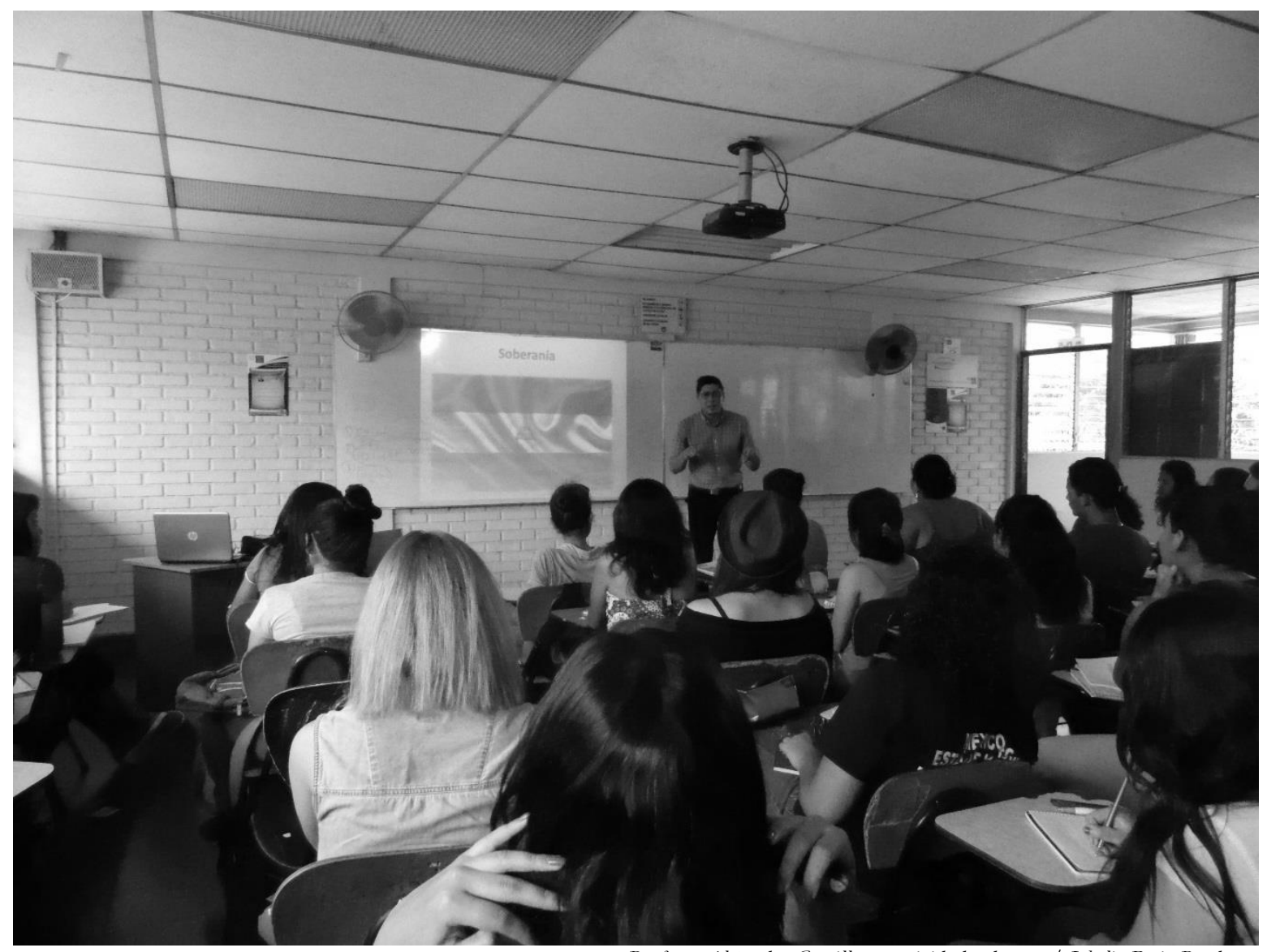

Profesor Alejandro Castillo en actividades docentes/ Isbelia Ruiz Perdomo.

El desarrollo del pensamiento humano parte y apunta hacia las libertades y demás derechos de la ciudadanía-pedagogías liberadoras, en la voz de Freire-, para lograr así estudiantes conscientes con el objetivo de construir una sociedad más justa e igualitaria. Por lo tanto, no puede haber desarrollo del pensamiento humano en la educación, sin el ejercicio o el conocimiento mismo de estas libertades. Con razón, Paiva opina que "es importante entender, que para que exista desarrollo del pensamiento, todos los seres humanos han de tener la oportunidad, la libertad de expresar sus ideas, opiniones y propuestas, y que a pesar del disenso que pueda surgir, se les respete su pensamiento"3.

Con el enflaquecimiento de la vocación de bienestar de los Estados y la proliferación del capitalismo neoliberal, los gobiernos han propiciado, a través de las estructuras de educación, una acelerada transformación de la funcionalidad social de la educación, hacia una funcionalidad de mercado. Boaventura de Sousa adjudica esta nueva funcionalidad de mercado de la universidad "a una crisis institucional", como consecuencia del actuar de las dictaduras latinoamericanas del pasado y el subsecuente neoliberalismo que llegó o continuó con la democracia al "poner la universidad al servicio del proyectos modernizantes autoritarios, abriendo al sector privado la producción del bien público de la

3 Andrews Paiva, "La educación liberadora de Paulo Freire y el desarrollo del pensamiento", Revista de Ciencias de la Educación. Año 5, 1 Vol. 21 N $^{\circ} 26$ l, (Julio-Diciembre 2005): 133-142. 
universidad y obligando a la universidad pública a competir en condiciones desleales en el emergente mercado de los servicios universitarios"4.

En este cambio de perspectiva, el derecho a la educación corre el peligro de perder su función liberadora de la persona humana ${ }^{5}$ al asumir una naturaleza radicalmente orientada a la reproducción y el sostén del sistema económico capitalista. En la lógica capitalista de educación, el estudiante es un factor que propicia y perpetúa un sistema basado en la adquisición y satisfacción compulsiva de deseos del consumo.

Actualmente, parte de los sistemas de educación superior sitúan de manifiesto su prioridad de educar estudiantes capaces de insertarse en el mercado y no en la sociedad. En consecuencia, la competitividad, la capacidad de cumplir metas bajo desmedida presión y la máxima posibilidad productiva, propios del sistema económico hegemónico, son los valores que no permiten una la formación social fundamentada en una lógica de promoción, garantía y defensa de derechos. De esta manera, se han visto surgir universidades que públicamente asumen estar al servicio de la empresa, de la innovación para el desarrollo o del progreso, es decir, la opción por la mercantilización de la universidad. ${ }^{6}$

Para lograr el cambio de paradigma educativo capitalista, es necesario que el estudiante transite del ser social al estudiante como agente de mercado y el docente como facilitador de la liberación al profesor-empresario, en las voces de Freire y Leher. ${ }^{7}$ Es particular, en el marco de esta compleja transición del ser al agente, la flexibilidad con que las estructuras educativas universitarias públicas o privadas involucradas en ajustarse a una dinámica capitalista del mercado, simbólica y materialmente excluyente y opresiva. Y quizá esto permita deducir la razón de los pocos quiebres estructurales o ideológicos sufridos por las universidades en su proceso hacia la mercantilización, pues aún sostienen viejas concepciones sobre cómo ellas asumen la función enseñanza-aprendizaje. En suma, el paradigma capitalista que piensa al estudiante como agente de mercado y no como ser social, es compatible con muchas concepciones, prácticas y lógicas que aún prevalecen en las instituciones de educación superior.

Algunas de estas concepciones, prácticas y lógicas de la educación superior -evocadoras más de sistemas dictatoriales que de los sistemas democráticos en los que se vive en este tiempo- son: (1) el maestrocentrismo o magistrocentrismo, en sí inherentemente desigual, proclama la superioridad académica del docente en detrimento del estudiante; (2) la

${ }^{4}$ Boaventura de Sousa Santos, La Universidad en el Siglo XXI. Para una reforma democrática y emancipatoria de la universidad. (La Paz, CIDES-UMSA, 2007), 24.

${ }^{5} \mathrm{Al}$ respecto del contexto y características de las pedagogías liberadora, Myriam Carreño, explica: "Estas pedagogías, a pesar de la diversidad, poseen algunos puntos en común que manifiestan la semejanza de inquietudes que recorrían la región. Tales características comunes hacen referencia al reconocimiento de la politicidad de la educación, a la denuncia de los factores de alienación provenientes del contexto económico y político y a la propuesta de transformación de la realidad, que contrasta fuertemente con el reformismo postulado por las pedagogías desarrollistas". Myriam Carreño, "Teoría y Práctica de una Educación Liberadora: el pensamiento pedagógico de Paulo Freire”, Revista Cuestiones Pedagógicas. Volumen 20, (2009), $195-214$.

${ }^{6}$ De Sousa, La Universidad, 27.

7 Roberto Leher, educador brasileño, menciona: "Há, assim, um novo ethos académico: o do professor-empreendedor, em que a universidade é uma peça na engrenagem do capital. A minha hipótese é que uma das novas funções da universidade é aumentar o exército industrial de reserva". "A submissão da universidade aos "mercados", Rubra Coletivo, consultado 15 de mayo de 2015.

http:/ /www.revistarubra.org/a-submissao-da-universidade-aos-mercados-entrevista-com-roberto-

leher/\#sthash.m2O25oRQ.dpuf 
relación verticalista autoridad-estudiantado; (3) la ausencia de instancias abiertas y horizontales para la discusión de la situación estudiantil; (4) el carácter excluyente e inobjetable de los claustros académicos y (5) prácticas de control corporal, mental de la producción creativa estudiantil o docente.

En este ensayo, se analiza la necesidad de centrar los derechos humanos como paradigma de la educación superior a fin de efectivizar el derecho a la educación como un instrumento liberador de la persona humana a través del abandono de las prácticas educativas que se hacen incompatibles con ese carácter emancipador, entre ellas el magistrocentrismo como elemento central del diálogo pedagógico predominante.

\section{Buscando un nuevo paradigma para la educación superior}

Ante un sistema de educación superior cada vez más anuente -aparentemente- con los intereses de la preparación para el mercado y con una práctica progresivamente desapegada de la vocación social de la relación enseñanza-aprendizaje, es necesario repensar el fundamento paradigmático en el que se está basando la universidad del presente.

Los Estados han consentido una serie de instrumentos internacionales que reafirman el carácter orientador de la educación hacia la realización humana a través del respeto de sus derechos. Por ejemplo, la Declaración Universal de Derechos Humanos, instrumento de mayor consenso y respeto en el contexto internacional sobre la materia, afirma:

\section{Artículo 26}

$[\ldots]$

1. La educación tendrá por objeto el pleno desarrollo de la personalidad humana y el fortalecimiento del respeto a los derechos humanos y a las libertades fundamentales; favorecerá la comprensión, la tolerancia y la amistad entre todas las naciones y todos los grupos étnicos o religiosos, y promoverá el desarrollo de las actividades de las Naciones Unidas para el mantenimiento de la paz. ${ }^{8}$

Por su parte, en el ámbito interamericano, el Protocolo adicional a la Convención Americana de Derechos Humanos, "Protocolo de San Salvador", respecto al derecho a la educación, establece para los Estados el deber de dirigirlo "[...] hacia el desarrollo de la personalidad humana". Y así, esta norma interamericana que contiene el derecho a la educación, es un claro reflejo de la necesidad de colocar los sistemas educativos hacia valores que actualmente no se corresponden con el ideal de mercado que las universidades proclaman. Es menester insertar el párrafo 1 y 2 del artículo 13 del Protocolo de San Salvador por su amplitud al describir el derecho a la educación a cargo de los Estados, el que no fue pensado (en 1988), de acuerdo al texto, desde la perspectiva actual que el sistema hegemónico pretende infundir a este derecho humano:

${ }^{88} \mathrm{El}$ texto de la Declaración Universal de Derechos Humanos está disponible en la siguiente dirección: http://www.un.org/es/documents/udhr/ 


\section{Artículo 13}

\section{Derecho a la Educación}

1. Toda persona tiene derecho a la educación.

2. Los Estados partes en el presente Protocolo convienen en que la educación deberá orientarse hacia el pleno desarrollo de la personalidad humana y del sentido de su dignidad y deberá fortalecer el respeto por los derechos humanos, el pluralismo ideológico, las libertades fundamentales, la justicia y la paz. Convienen, asimismo, en que la educación debe capacitar a todas las personas para participar efectivamente en una sociedad democrática y pluralista, lograr una subsistencia digna, favorecer la comprensión, la tolerancia y la amistad entre todas las naciones y todos los grupos raciales, étnicos o religiosos y promover las actividades en favor del mantenimiento de la paz. ${ }^{9}$

$[\ldots]$

Una educación desprovista de ese sentido común, hacia esa aspiración de respeto de los derechos humanos y las libertades fundamentales, es una educación que no es compatible con la necesidad de formar estudiantes comprometidos con la resolución de las grandes problemáticas que aquejan a la humanidad. Y es precisamente, en la labor de repensar la lógica paradigmática de la universidad del presente, que los derechos humanos emergen como vía válida para reorientar por un lado, lo que hemos llamado la educación que forma al estudiante como factor de mercado hacia la educación que forma seres sociales y por el otro, desafiar estas viejas lógicas y prácticas arraigadas en los sistemas de educación superior que evidencian sus tensiones con un discurso centrado en la persona y que la hacen funcional con el arquetipo capitalista. En síntesis, los derechos humanos pueden ser parte de lo que De Sousa contempla como un "[...] único modo eficaz y emancipador... una globalización alternativa, una globalización contrabegemónica"10, como mecanismo alterno para el salvamento de la situación actual de la universidad. ${ }^{11}$

\section{El paradigma de los derechos humanos como nueva vía para la emancipación en una sociedad democrática}

La democracia como valor no sólo debe estar presente en los órganos desde los que visiblemente se ejerce el poder político, sino también en cada una de las esferas y entidades tanto del Estado, como de la sociedad misma. Vivir en democracia, involucra necesariamente, tal como se entiende hoy, que el Estado asuma los derechos humanos como su lógica operacional y como fundamento mismo de sus actos. Del mismo modo se espera que la educación, ya sea entendida como un sistema o como contenidos de las materias, esté también inspirada y movida desde una perspectiva de derechos humanos; una educación consciente de que la realización de aquellos son la grande aspiración del aparataje estatal y, por consiguiente, de la sociedad.

\footnotetext{
${ }^{9} \mathrm{El}$ texto del Protocolo de San Salvador está disponible en la siguiente dirección: http://www.oas.org/juridico/spanish/tratados/a-52.html

${ }^{10} \mathrm{El}$ énfasis es agregado-

${ }^{11}$ De Sousa, La Universidad, 52.
} 
La instalación de los derechos humanos como paradigma de la educación superior, entraña incluso, tanto un cambio ideológico, como un cambio estructural. En el ámbito ideológico, el paradigma de derechos humanos, por ejemplo, hace vital un trato igualitario conforme la dignidad inherente de cada persona, lo que presume la supresión de discursos y mecanismos educativos tendientes a la discriminación. Es decir, la universidad puede procurar un aula propicia para la eliminación de estereotipos sobre quién es el estudiante/docente ideal, de dónde proviene, qué lo hace más importante o valioso, tanto dentro del ambiente académico, como en el futuro profesional.

Por otra parte, la dignidad como uno de los parámetros del amplio espectro del paradigma de derechos humanos, supone la puesta en duda del mismísimo diálogo pedagógico concentrado en el docente. Este tipo de diálogo es inherentemente desigual, al situar al estudiante en una relación de sumisión, subordinación y silencio ante la inobjetable figura docente.

Los derechos humanos como instrumento, pueden cambiar la dinámica en que se organiza y se piensa el sistema de educación superior en su totalidad, al persuadir a todos los agentes vinculados a pensarlo todo desde los derechos bumanos. Visto de otro modo, Hevia propone, "[no] una enseñanza de o sobre los derechos humanos, sino una enseñanza para el ejercicio de los DDHH"12. Es decir, un sistema que reflexiona y se mueve hacia un derecho a la educación como herramienta, que asegura una vida que permita a cada quien el cubrimiento de las necesidades plenas de existencia -y no de subsistencia, como afirma el discurso de los Estados desentendidos de su vocación de justicia social-. Una educación que piensa la protección de la integridad del otro, que abandera la libertad de pensamiento, que no reprime las diferencias ideológicas.

El paradigma de derechos humanos puede incentivar una educación pensada para la solidaridad social no filantrópica, una solidaridad democrática -descrita por Lavilleconstruida a partir del avance real de los grupos sociales en situación de vulnerabilidad gestada desde el aula. Lo anterior desafía a que, estudiantes y docentes, se transformen en actores propiciadores de la justicia social y mediante ésta, del respeto de las diferencias sin generar exclusión o empeoramiento de la situación que cada cual vive: educar para la diversidad.

La educación superior basada en el paradigma de derechos humanos, apunta hacia la inclusión sin atisbos de los grupos sociales en situación de vulnerabilidad, como expresión de su disposición por la diversidad. Y aquí una de las principales responsabilidades de la universidad actual, puesto que la exclusión histórica que han sufrido los grupos en situación de vulnerabilidad en el acceso a la educación terciaria (por ejemplo, las personas en estado de pobreza, provenientes de comunidades étnicas no mayoritarias o personas transexuales) puede acentuarse aún más si se prefiere la funcionalidad con la globalización neoliberal, sistema que ha demostrado ser factor de exclusión y profundización

12 Ricardo Hevia Rivas, "El Derecho a la Educación y la Educación en Derechos Humanos en el contexto internacional”. Revista Latinoamericana de Educación Inclusiva", consultado 17 de mayo de 2015.http://www.rinace.net/rlei/numeros/vol4num2/art1.pdf, 9, Consultado 17 de mayo de 2015. 
generalizada del contexto de estos grupos. ${ }^{13}$ El Comité DESC ha subrayado, en la Observación General No. 13, que la no discriminación es elemento integrante de accesibilidad en la educación: "[...] La educación debe ser accesible a todos, especialmente a los grupos vulnerables de hecho y de derecho, sin discriminación por ninguno de los motivos prohibidos"14.

La universidad basada en derechos, puede entonces proseguir hacia una educación para la diversidad, inspirada, por ejemplo, en la Convención contra la discriminación en la educación (1960), los referentes sobre educación de los Principios sobre la aplicación de la legislación internacional de derechos humanos en relación con la orientación sexual y la identidad de género (2007), las resoluciones de la Conferencia Mundial de Durban (2001) que prohíben la discriminación hacia personas afros e indígenas y en este mismo sentido, las disposiciones del Convenio 169 OIT sobre pueblos indígenas y tribales (1989) o la Declaración Universal de la UNESCO sobre la Diversidad Cultural (2001).

Por otro lado, se podría lograr un clima de democracia que rompa las barreras del verticalismo propio de las formas de dirección en la educación superior. Los derechos humanos en la universidad requieren -como lo veremos más adelante- un clima de democracia, pues la universidad debe ser un espacio seguro para ejercer derechos, para ser plenamente ciudadano. La universidad tiene ante sí un reto fundamental para poder cambiar hacia el paradigma de derechos humanos, el de luchar contra las prácticas opresoras que permean su ideología y que forman parte de otro contexto más amplio: la cultura autoritaria de nuestras sociedades latinoamericanas.

La universidad, por tanto, puede ser un eslabón importante hacia la consolidación de la democracia y ser en sí misma, testimonio de que la educación superior puede ser sinónimo de democracia real, participativa e inclusiva y no reflejo de ser parte de un mecanismo integrante del raciocinio excluyente y mercadocéntrico del capitalismo neoliberal. La universidad debe ser democrática, en una realidad que hace necesario de que así lo sea, por lo que es menester tener en cuenta que:

La democracia no se instaura por decreto, no es sólo forma, sino esencialmente fondo. Por ello los cambios más prolongados y profundos se reflejan en las prácticas reales de los sujetos sociales. En este sentido, la educación formal (escolarizada) e informal (la que se crea en espacios como el de la familia, el trabajo, la iglesia y otros) son fundamentales para la

\footnotetext{
13 De Sousa explicará la dicotomía entre accesibilidad de grupos y democratización en la universidad en los siguientes términos: "En el área del acceso la mayor frustración de la década fue que el objetivo de la democratización del acceso no fue conseguido. En la mayoría de los países los factores de discriminación, sean ellos la clase, la raza, el sexo o la etnia, continuaron provocando en el acceso una mezcla entre mérito y privilegio. En lugar de la democratización, hubo masificación y luego, en el período de la controvertida postmasificación una fuerte segmentación de la educación superior con prácticas de auténtico dumping social de diplomas y diplomados sin que hayan sido tomadas de manera eficaz medidas anti-dumping. Las universidades de los segmentos más altos tomaron muy pocas iniciativas, además de defender sus criterios de acceso, invocando el hecho, muchas veces cierto, de que las más persistentes discriminaciones ocurren antes de la universidad en la educación primaria y secundaria". (De Sousa, La Universidad, 60 y 61).

${ }^{14}$ Naciones Unidas, Recopilación de las Observaciones Generales y Recomendaciones Generales adoptadas por órganos creados en virtud de tratados de derechos humanos: Observación General Número 13, Comité DESC. $20^{\circ}$ Período de Sesiones (1999), Párr. 6, b), i. Documento electrónico: http://www.servindi.org/pdf/ObservacionesyRecomendacionesGenerales.pdf Acceso: 17 de mayo de 2015.
} 
reproducción del sistema autoritario o bien para la democratización de éste. ${ }^{15}$

Ahora bien, apenas con los acercamientos que hemos hecho sobre los derechos humanos como paradigma del derecho a la educación, es evidente que nada de esto puede ser posible plenamente, de continuarse con una mirada capitalista de la educación (el estudiante como agente de mercado) o, con las formas y prácticas magistrocéntricas. En los siguientes apartados, intentaremos analizar algunos escenarios que podrían repensarse para la incorporación de este nuevo paradigma de derechos humanos.

\section{Repensar las lógicas, concepciones y prácticas de la educación superior para seguir el camino de los derechos humanos}

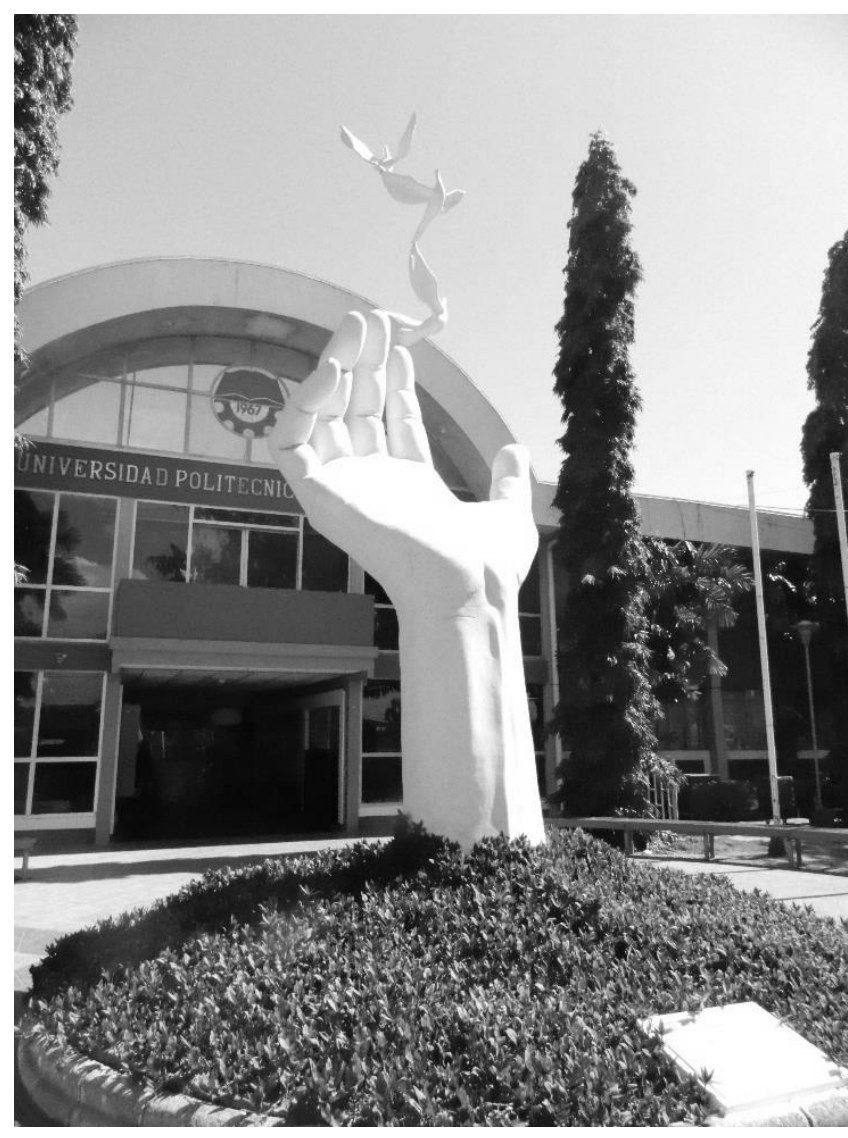

"Mano de la paz" de M. Governatori/ Isbelia Ruiz Perdomo.

Repensar las lógicas, concepciones y prácticas en las que se fundamenta la educación superior para dirigirla hacia un paradigma de derechos humanos, es reconstruir y desconstruir sus bases ideológicoestructurales. Meditar el qué hace la universidad, cómo se ve hacia dentro y hacia fuera, a quiénes admite como sus actores plenos y cuál es el tratamiento que les $\mathrm{da}$, es fundamental para determinar su funcionalidad social actual. En todo caso, una universidad abierta a efectivizar el derecho a la educación, pensará en los derechos humanos y la democracia como instrumento de pedagogía social para la modificación de la generalizada realidad adversa al desarrollo de la autonomía humana prevalente en nuestros días.

La universidad debe seguir asumiendo su papel como actor social presente desde la educación en todas las dinámicas y debates sociales $y$ abandonar las circunstancias que posibiliten el aislamiento en el que puede estar ubicada, tras convertirse en una empresa más por la que pasa el estudiante antes de insertarse en la desmedida lucha del mercado. En lugar de aislarse para ser una pieza más en el engranaje del capitalismo, la educación superior debe ser parte de los movimientos sociales que

15 Alejandro Álvarez Martínez, "Educación para la ciudadanía México: educación, autoritarismo y democracia en los albores del siglo XXI". (Ponencia presentada en el Congreso Iberoamericano de Educación, Buenos Aires, 13-15 de septiembre de 2010). Disponible en: http://www.rinace.net/rlei/numeros/vol4-num2/art1.pdf Consultado 17 de mayo de 2015. 
cuestionan las consecuencias para la humanidad de un sistema económico apático con la sostenibilidad de la vida del cosmos, a través de la vigencia real de los derechos humanos.

\section{Superar los modelos excluyentes}

Pensar al derecho a la educación desde una representación de derechos humanos, nos hace cuestionar los modelos sobre los que están asentados el currículo, la actividad académica y sobre todo, la legitimidad de la noción tradicional de quién produce y quién es destinatario de la teoría en la academia. El paradigma de derechos humanos en la educación obliga a desmantelar la sacralizada posición y los poderes del docente en el aula de clases en cuanto a su autoridad, delimitación de contenidos o control mental, creativo o corporal de la persona estudiante. Todo lo anterior, configura el magistrocentrismo basado en una versión exacerbada de la autoridad docente, el autoritarismo al que Álvarez se refiere:

Podemos ver cómo existe una idea tergiversada del respeto a la autoridad, ya que en realidad esta última se convierte en autoritarismo. La autoridad se basa en la legitimidad, en el respeto a las normas consensadas y en la voluntad de la mayoría. El profesor goza de esta legitimidad de origen pues se acepta de manera tácita que se encuentra preparado para ser un guía, coordinador y líder en el proceso de aprendizaje. ${ }^{16}$

Ese mismo paradigma se hace esencial desconocer de una vez por todas al estudiante como sujeto pasivo del diálogo pedagógico y ubicarlo por fin en posición de igualdad con el docente, en tanto que a igual capacidad para interpretar y modificar el entorno y el contexto social. Un diálogo pedagógico real, de doble vía, donde tanto enseñanza como aprendizaje, son instrumentos sociales de educación igual de importantes. Y quizá, este último aspecto sea uno de los que el background ideológico de la universidad actual, es reacia en abandonar. Al reconocer la igualdad entre aprendizaje-enseñanza, está persuadida a crear cada vez más mecanismos abiertos de participación en las decisiones de la administración del currículo, de la vida universitaria. Conexo con lo anterior, insertamos la reflexión que Evangelista Márquez comparte al respecto:

En esta situación, en el profesor se centra todo el poder y todo el saber, y es quien ocupa el lugar más importante del salón de clase. ¿Dónde está entonces el cambio de paradigma pedagógico? ¿Cuándo el estudiante ocupará el lugar más importante en el proceso enseñanza-aprendizaje? ¿Para qué pregonar tanto la teoría constructivista si solo la vemos (sin realmente entenderla y mucho menos ponerla en práctica) y no la comprendemos en la extensión de la palabra? El alumno no es visto como tal, la relación maestroalumno no se da, o se pierde, ya que la "enseñanza" impartida por este tipo de docente es de carácter unilateral: él solo va a ser un trasmisor y no le

16Álvarez Martínez, "Educación para la ciudadanía", 5. 
interesa si el alumno aprende o no, si comprende lo que se ve en clase o no, lo más importante es terminar el programa. ${ }^{17}$

El cuestionamiento de este background ideológico nos permite ir a razonamientos más profundos: el paradigma de derechos humanos también permitiría criticar la manera habitual en que se entienden y se estructuran a sí mismos los colectivos académicos, la función docencia y el docente mismo. La idea de creer al docente como elegido exclusivo, a la función docencia como su función natural o la producción científica como legítima si es producida desde la academia, puede ser compatibilizada con una apertura destinada a considerar que todo lo anterior es aún más útil, cuando se logra valorizar, experimentar y reconocer los saberes y vivencias de la persona estudiante en el desarrollo de las actividades de enseñanza. Atinadamente Paiva, cita a Freire afirmando:

...el educador ya no es sólo el que educa sino aquel que, en tanto educa, es educado a través del diálogo con el educando, quien, al ser educado, también educa. Así, ambos se transforman en sujetos del proceso en que crecen juntos y en el cual "los argumentos de la autoridad" ya no rigen. Proceso en el que ser funcionalmente autoridad, requiere el estar siendo con las libertades y no contra ellas. ${ }^{18}$

Finalmente, es necesario poner en la crítica el academicismo y la pertenencia en sí a la academia cuando se gesta como una cuestión o agrupación sectaria, excepcional o privilegiada en detrimento o en exclusión de la persona estudiante y por extensión, de los sectores sociales mismos. Este tipo de conformaciones e interpretaciones sobre el ser académico y la de las funciones académicas, dan cuenta del carácter antidemocrático y generador de exclusiones que prevalece en la educación superior. No puede haber una noción de superioridad o exclusividad en un sistema educativo que piensa el mérito académico no como prerrogativa, si no como instrumento representativo de su función de resguardo de los derechos humanos. He ahí uno de los quiebres y contradicciones del modelo capitalista de educación con el modelo basado en derechos humanos.

\section{El diálogo pedagógico centrado en la dignidad}

Si la dignidad humana es el tratamiento que cada humano merece del otro, de ser considerado igualmente importante o valioso, esto quiere decir que la educación superior debe pensar la centralidad del ser humano en todos los procesos curriculares. La idea capitalista de la educación, asocia al ser humano más que como ente social, como un número apto, entre otros tantos números - población estudiantil o docente- que pueden serle útiles dentro del sistema de mercado. La educación superior basada en los derechos humanos rompe con esta visión utilitaria del estudiante y el docente, en pro solamente del mercado hegemónico y los reconoce como una entidad social parte de una comunidad diversa.

${ }^{17}$ José Luis Evangelista Márquez, "El docente autoritario" Revista Synthesis, No. 45, Chihuahua, Universidad Autónoma de Chihuahua, (2008) P. 2.

18Paiva, La educación liberadora, 139. 
La centralidad del ser humano estudiante y su condición de igualmente digno, valioso e importante, es ausente en diversas entidades de educación superior asentadas aún en el magistrocentrismo, en el docente autoritario, la verticalidad autoridad académica-estudiante o el academicismo sectario. Esto es verdaderamente alarmante, si se tiene en cuenta que estas estructuras universitarias fundadas en estos valores, pueden ser comprendidas como herederas de los sistemas dictatoriales estatales que no hace mucho y, en otros contextos sociales, hacían prevalecer estos mismos valores. Derechos humanos y herencia dictatorial no son sistemas convergentes.

Ahora, si la centralidad estudiante o docente como seres humanos es fundamental para la universidad comprometida con una educación liberadora desde los derechos humanos, entonces es también primordial el abandono de viejas prácticas de control que atentan contra la libertad en todos sus sentidos posibles, más si se piensa a la libertad misma como una de las realizadoras de la propia dignidad humana. En este sentido, enfatizamos tres prácticas alarmantes aún vigentes:

1. El control del cuerpo, ${ }^{19}$ mecanismo consistente en el aseguramiento excesivo del estudiante en el entorno físico de las entidades universitarias donde se cursan las carreras. Para fortalecer este mecanismo de control, se añade distintas formas para lograrlo, tal como la sanción por la ruptura del tiempo obligatorio de presencia. Esto evoca la práctica del capitalismo asociada con el cumplimiento de metas sin el consentimiento del trabajador o sin tener en cuenta su particular capacidad para adecuarse a entornos tan estandarizados.

No queremos expresar con lo anterior que no deben existir mínimos en cuanto a la presencia física de los estudiantes en los entornos físicos, si no que esta presencia sea pensada conjuntamente sobre la base del consenso con el estudiantado, la cantidad de horas pedagógicamente adecuadas para el desarrollo de las clases y conexo a esto, los efectos psico-corporales de la cantidad media horas en un aula para el estudiante. Todo lo anterior, debería llevar a la universidad actual a repensar conceptos tales como presencia y salón de clases que podrían necesitar una actualización. Scharagrodsky opina:

El discurso pedagógico moderno supuso la distribución rigurosa de los cuerpos. De hecho, en el siglo XVII surgió el concepto de salón de clases, aspecto muy importante ya que diseñó una cuadrícula en la que cada celda le correspondió a un cuerpo. Todos estaban vigilados

\footnotetext{
${ }^{19}$ Sobre la visión moderna del cuerpo, Scharagrodsky opina: "La visión moderna del cuerpo en las sociedades occidentales ha naturalizado la visión corporal como fuera de la historia. Sin embargo, parafraseando a Foucault, cualquier análisis políticopedagógico y escolar debe identificar la articulación del cuerpo y de la historia: "debe mostrar al cuerpo impregnado de historia, y a la historia como destructora del cuerpo. El cuerpo es la superficie de inscripción de los sucesos (mientras que el lenguaje los marca y las ideas los disuelven), lugar de disociación del Yo (al cual intenta prestar la quimera de una unidad substancial), volumen en perpetuo derrumbamiento. Sobre el cuerpo, se encuentra el estigma de los sucesos pasados, de él nacen los deseos, los desfallecimientos, los errores; en él se entrelazan y de pronto se expresan, pero también en él se desatan, entran en lucha, se borran unos a otros y continúan su inagotable conflicto" (Foucault, 1992: 14).”. Pablo Scharagrodsky, El cuerpo en la escuela. (Buenos Aires, Ministerio de Educación, Ciencia y Tecnología). http://explora.educ.ar/wpcontent/uploads/2010/04/PEDAG05-El-cuerpo-en-la-escuela.pdf Consultada 18 de mayo de 2015.
} 
por un adulto que, generalmente, ocupó el lugar del saber y de la autoridad. ${ }^{20}$

2. El control de la construcción creativa que radica en la necesidad de las entidades de investigación de orientar la producción de la actividad del estudiante mediante líneas infranqueables, primero sostenida mediante el discurso docente -incontrovertible, claro- y luego a través de los medios de evaluación. Esto evidencia enfoques y contenidos ofrecidos e impuestos como únicos límites válidos desde una perspectiva que no necesariamente respeta, no sólo los conocimientos o cosmovisiones del estudiantado, sino que, además, es incompatible con la diversidad de visiones necesaria en una democracia educativa. Esta práctica es factible en su totalidad con el raciocinio capitalista del mercado como la medida única de las cosas y la explicación del todo.

3. El control de la cooperación. ¿La educación retributiva o contributiva? Tal como el orden internacional capitalista condiciona la ayuda técnica o financiera que destina a los países en desarrollo, la educación superior hace lo mismo muchas veces con la persona estudiante o docente. De esta manera, la entidad superior que debería contribuir con cualquier esfuerzo que esté a su disposición, incluso material, para asegurar la formación del estudiante o desarrollo funcional del docente, se transforma en un instrumento de retribución al exigir de la persona estudiante o docente, determinados actos o tareas (proporcionalidad estandarizada de horas, de trabajo, de producción académica), en lugar de propiciar la creación de entornos de creatividad, de emprendimientos bajo el consenso de estándares base.

En este punto de la discusión, es interesante resaltar un rol que el tradicional magistrocentrismo autoritario ha asumido: el papel inquisitorial del proceso pedagógico. En mente los mecanismos de control que mencionamos en el apartado anterior, las direcciones de las entidades de educación asignan a la persona docente esta función piénsese en la institución eclesiástica de la Inquisición surgida en la Edad Feudal-toda vez que crea un clima de permanente persecución, sujeción y desconfianza hacia la persona estudiante, dañando su integridad física y mental. No todas las personas docentes están dispuestas a asumir funciones policiales o de control sobre el estudiante; no obstante, el temor a la desobediencia o las consecuencias pecuniarias, hacen expresar una y otra vez al docente: "es una orientación de la dirección". Esta función inquisitorial del docente es la versión aggiornada en la que cumple un puesto en la economía del capital: el docente como capataz en potencia, emulador de las futuras relaciones de autoridad con el jefe del empleo, al que estará subordinado todo nuevo elemento del capital humano en el futuro.

Hemos anotado algunas situaciones que, de ser superadas, las entidades de educación superior estarán cada vez en mayor cercanía para discutir y poner de manifiesto al estudiante como razón existencial de la academia misma y no lo contrario.

${ }^{20}$ Scharagrodsky, El cuerpo en la escuela, 5 y 6. 


\section{La lógica empresarial del posgrado: la universidad como formadora de capital humano}

Aún prevalecen otros males infiltrados del pensamiento del mercado hegemónico, tal como la de considerar la formación profesional posgraduada como vía privilegiada para acceder a una serie de condiciones de vida o de consumo, que otras personas de la misma sociedad no pueden acceder. Entonces, las personas recorren una búsqueda incesante por acumular posgrados en las mejores universidades posibles como garantía para la acumulación de privilegios salariales y estatus dentro del mercado. Lo peor que hay instituciones de educación superior encajando en esta lógica, que han hecho de la especialización posgraduada, un negocio que compite con otras instituciones del mismo orden. Esta es la universidad que vende servicios para la competitividad global, estableciendo criterios excluyentes como mayor cantidad de idiomas posibles, antecedentes profesionales o referencias de renombre y no la que facilita un instrumento de liberación social.

Esta universidad que ofrece servicios para la competitividad, degrada la función social de la educación, pues excluye a aquellos estudiantes y docentes, que no necesariamente, sus contextos o visiones de vida, están relacionados o pensados ni material, ni ideológicamente para el mercado. En este marco -decíamos arriba- la educación puede ser una pieza más del engranaje capitalista: la educación como una empresa. En la empresa, la persona más bábil o dedicada con entereza a las metas de producción o ventas, es la que avanza mejor en esas feroces estructuras. Este razonamiento es el que prevalece en la universidad que privilegia el mérito de la brillantez, por encima del aprecio de la diversidad individual.

Así es cómo las universidades se transforman en verdaderas entidades que dejan su vocación de formación de seres sociales, por la preparación de seres aptos para el mercado: la universidad como formadora de capital bumano (o, capital bancario en la voz de Freire). En las relaciones productivas del sistema hegemónico actual, capital humano no es sinónimo de ciudadanía, mucho menos de sujeto de derechos. Al no ser aspiraciones interdependientes, el capital humano -material viviente al servicio de la economía empresarial- deviene en la cosificación y luego en la masificación, hasta el punto de no distinguirse a sí mismos como factores que producen y consumen bienes y servicios o como ciudadanos con consciencia social (la idea capitalista del consumo como ejercicio de derechos o ciudadanía del consumo).

\section{La persona estudiante como sujeto pleno de la construcción y transformación educativa: su papel en el paradigma educativo de derechos humanos desde el pensamiento freiriano}

En la propuesta de Freire, como ya se ha dicho, el desarrollo del pensamiento humano parte y apunta hacia a la pérdida del miedo, de vivir las libertades y a la afirmación de los derechos humanos-pedagogías liberadoras-. Su objetivo es promover la concientización y la construcción de una sociedad más justa e igualitaria, a través de la oportunidad de expresar las ideas, puntos de vistas y propuestas. Es necesario, para ello, que se establezca una lógica horizontal de educación donde el diálogo (aunque surjan disensos) y el intercambio de saberes, tome el lugar del maestro como el centro. 


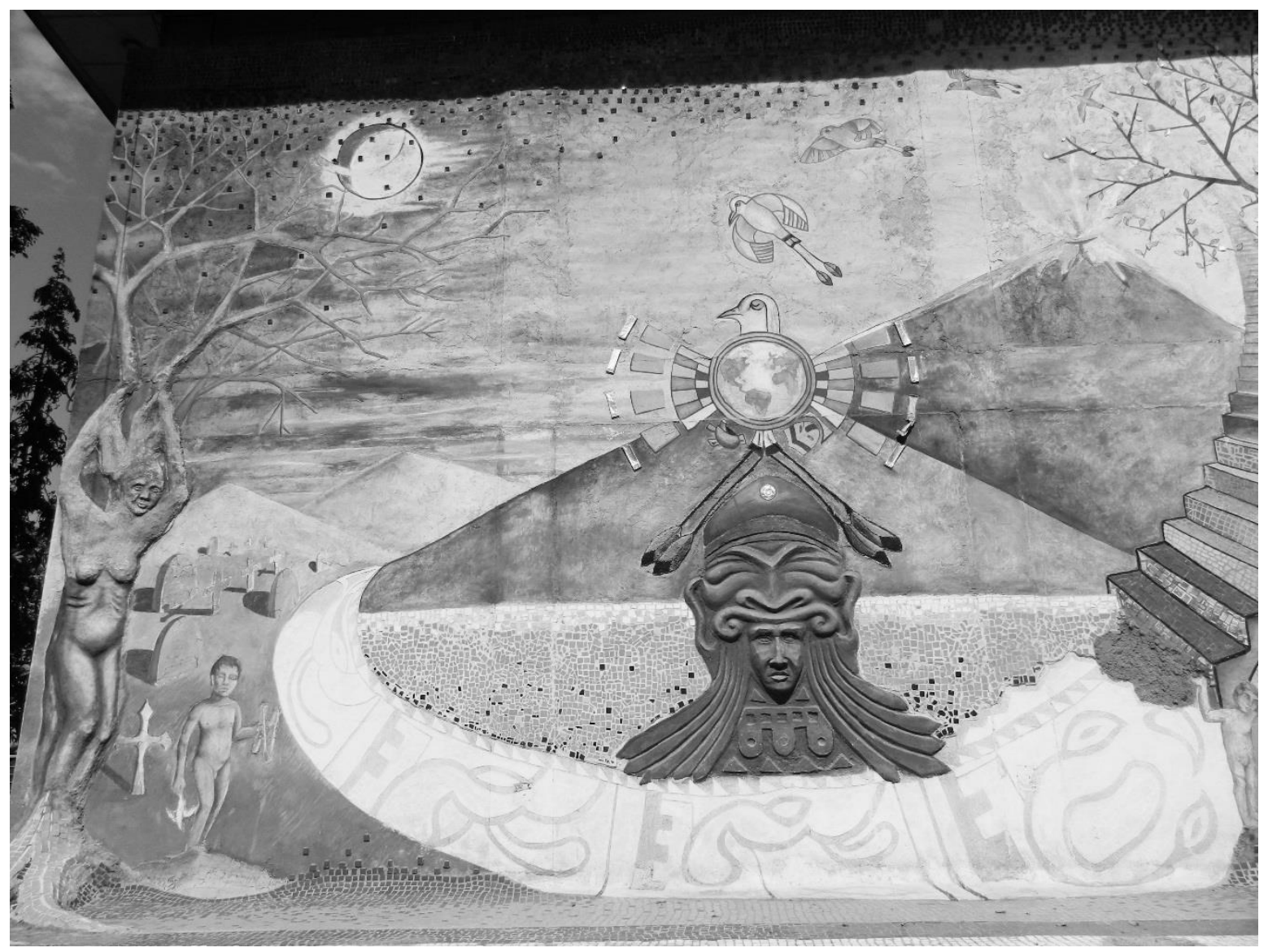

Foto: Isbelia Ruiz Perdomo.

Al asumir la lógica de la horizontalidad y del diálogo, la educación propone la emancipación y el foco en el estudiante, al comprender el lugar protagónico que le corresponde en su formación. Esta lógica pretende confrontar el mundo intrínsecamente injusto, capitalista y generador de la miseria humana interpretado por Freire, donde los poderes siempre buscan aplastar a los sin poder, silenciando la palabra, deshumanizando los sujetos, generando una consciencia del oprimido fatalista y auto subvalorada. Esta dinámica pretende hacer con que la "debilidad de los oprimidos se convierta en la fuerza capaz de inaugurar la justicia”.

Sin embargo, la voz de los estudiantes no puede estar restricta al espacio del aula. Sus ideas y propuestas deben servir como orientadoras en la construcción de la educación universitaria. En Freire, el oprimido debe ocupar la esfera pública para debatir y decidir de forma democrática a tal punto que pueda incidir efectivamente en la concreción de los derechos humanos desde una perspectiva amplia y que pueda generar oportunidades a todos los actores sociales involucrados, potenciando la visión de las personas estudiantes.

Es fundamental la implantación de la participación de los estudiantes en las instancias de decisión. La democratización de esos espacios, según Freire, es el instrumento para que la comunidad estudiantil pueda cambiar la lógica de opresión históricamente construida, inclusive, desde los espacios de dirección universitaria. Además, es importante fortalecer la compresión de que, aún en universidades privadas, la educación es un bien público 
orientado a la construcción del sujeto como actor político y social, por tanto, es inadmisible que las universidades privadas excluyan o nieguen la participación activa y plena del estudiante o los docentes, al alegar o insinuar que los grupos dirigentes son albaceas insustituibles de los proyectos filantrópicos, religiosos o de cualquier índole que dieron origen a la fundación de cualquier universidad privada. Como sostiene el autor, la crisis de la educación se da, precisamente, porque la educación no está pensada por la sociedad, sino hecha para ella.

Así, un punto imprescindible es posibilitar que las directrices curriculares sean pensadas para la democracia. Es decir, que en la elección y formulación de los contenidos se tenga en claro el rol emancipador, colectivo y participativo de la educación promotora de los derechos humanos y de la justicia, rompiendo así con las lógicas verticalistas y opresoras de construcción del conocimiento. Como sostiene Freire, la liberación implica autonomía, responsabilidad y la incorporación de la praxis libertadora. En esa dialéctica se propone que la educación popular sea el instrumento de la mediación entre la consciencia y el mundo, tornarse el motor del cambio de la lógica de la educación.

Finalmente, la universidad debe servir como sitio ejemplar para concretar derechos. Para tanto, habrá que promocionar ámbitos, acciones y medidas de sensibilización dirigidas a la erradicación de patrones socio-culturales que sostienen o consienten con prácticas discriminatorias, excluyentes y otras formas de violencia, teniendo así el paradigma y el ejercicio de los derechos humanos como fuente, razón y faro de la educación universitaria.

\section{Una nueva dinámica pedagógica para la universidad, la educación popular}

Implementar la educación popular es romper con la lógica hegemónica capitalista, para proporcionar los instrumentos necesarios para el desarrollo de iniciativas emancipadoras desde de una perspectiva de derechos humanos, a través del relevamiento de experiencias, intercambio de saberes y de la difusión de herramientas y contenidos disponibles para el ejercicio y goce de dicho paradigma. La transformación de las estructuras mercantilistas de la educación constituye una tarea permanente. Democratizar los espacios de toma de decisión, de la palabra y la reflexión crítica, valorando la diversidad y la dignidad de los actores involucrados y tener como foco prioritario al estudiante en la educación popular.

Partiendo del supuesto freiriano que cualquier práctica educacional, no es neutra, posee ética, estética y dimensión política, la educación popular está comprometida con la producción y reproducción digna de la vida, por ende, de los derechos humanos. Su rol comprometido con la ruptura con de las estructuras de capitalismo mercantilista, generador de transformación social centra su pedagogía en cuatro puntos:

a. El reconocimiento de los saberes, vivencias y experiencias del estudiante como punto de partida de la construcción pedagógica. El intercambio de conocimiento como herramienta de transformación social, que pueda posibilitar la conciencia, la comunicación dialógica y el involucramiento en la construcción de procesos liberadores. 
b. La organización y participación del estudiante que pueda romper con las normas pedagógicas centradas en el docente, en la formalidad, en los dictámenes de la educación como productora de capital humano. El involucramiento del estudiante en los procesos decisorios genera pertenencia, responsabilidad, sentido crítico y autocrítico, empoderamiento personal y consciencia política.

c. El diálogo pedagógico como superación de la opresión, de los contextos autoritarios, de los mecanismos promotores de exclusión y discriminación. La lógica de la acción dialógica debe asumir el estudiante como protagónico y establecer formas democráticas de enseñanza y aprendizaje, rompiendo con el autoritarismo y opresión. La libre circulación de las ideas y de los cuerpos generan argumentación, a través de la problematización y de la búsqueda de conocimiento, libre de la coerción y presión recurrentes en los espacios formales de educación.

d. La promoción de la dignidad humana como elemento fundador del proceso pedagógico que posibilite el encuentro con el humano, con la valoración de la diversidad, de la concretización de la educación popular universitaria como elemento de transformación social desde supuestos de los derechos humanos.

En el contexto del sistema hegemónico capitalista, en permanente tensión con la reproducción de la vida digna de los grupos sociales, la universidad del siglo XXI-como la nombra De Sousa-tiene ante sí el reto de seguir pensándose como un espacio social de reacción, de debate y de alternancia. Un espacio que, centrado en el paradigma de los derechos humanos, sea capaz de procurar un diálogo pedagógico que reivindique la centralidad del ser humano y de los grupos históricamente excluidos, en oposición con el capitalismo que rencilla por desplazarlos en aras de dar ese lugar al mercado. La universidad de nuestros tiempos, basada en la educación popular como mecanismo para la instalación del paradigma de derechos humanos, educa para la vida, para la liberación y para la emancipación definitiva de los oprimidos.

\section{Bibliografía}

Naciones Unidas. "Recopilación de las Observaciones Generales y Recomendaciones Generales adoptadas por órganos creados en virtud de tratados de derechos humanos: Observación General Número 11, Comité DESC. $20^{\circ}$ Período de Sesiones (1999)" Consultado 16 de mayo de 2015. Disponible http://www.servindi.org/pdf/ObservacionesyRecomendacionesGenerales.pdf

Paiva, Andrés. "La educación liberadora de Paulo Freire y el desarrollo del pensamiento". Revista de Ciencias de la Educación. Año 51 Vol. 21 N$^{\circ} 26$ 1, (juliodiciembre 2005): 133-142. 
De Sousa, Boaventura. La Universidad en el Siglo XXI. Para una reforma democrática y emancipatoria de la universidad. La Paz: CIDES-UMSA, 2007.

Carreño, Myriam. “Teoría y Práctica de una Educación Liberadora: el pensamiento pedagógico de Paulo Freire”. Revista Cuestiones Pedagógicas, Volumen 20. (2009): 195-214.

Rubra Coletivo. "A submissão da universidade aos "mercados"”. Rubra Coletivo. Consultado 15 de mayo de 2015. http:/ /www.revistarubra.org/a-submissao-dauniversidade-aos-mercados-entrevista-com-robertoleher/\#sthash.m2O25oRQ.dpuf

Asamblea General de Naciones Unidas. "Declaración Universal de Derechos Humanos", Consultada 15 de mayo de 2015, http://www.un.org/es/documents/udhr/

Departamento de Derecho Internacional de la Organización de Estados Americanos. "Protocolo de San Salvador". Consultado 19 de mayo de 2015, http://www.oas.org/juridico/spanish/tratados/a-52.html

Hevia, Ricardo. "El Derecho a la Educación y la Educación en Derechos Humanos en el contexto internacional". Revista Latinoamericana de Educación Inclusiva. Vol. 14, No. 2, consultada 17 de mayo de 2015.http://www.rinace.net/rlei/numeros/vol4-num2/art1.pdf (2010)

Martínez, Alejandro. "Educación para la ciudadanía México: educación, autoritarismo y democracia en los albores del siglo XXI" Ponencia presentada en el Congreso Iberoamericano de Educación, Buenos Aires, 13-15 de septiembre de 2010. Consultada 17 de mayo de 2015. http://www.rinace.net/rlei/numeros/vol4num2/art1.pdf

Evangelista, Márquez J. “El docente autoritario”, Revista Synthesis, No. 45 (2008): 2.

Scharagrodsky, Pablo. "El cuerpo en la escuela". Buenos Aires: Ministerio de Educación, Ciencia y Tecnología, 2010. Consultada 18 de mayo de 2015. http:/ / explora.educ.ar/wp-content/uploads/2010/04/PEDAG05-El-cuerpoen-la-escuela.pdf 